\title{
chimeres
}

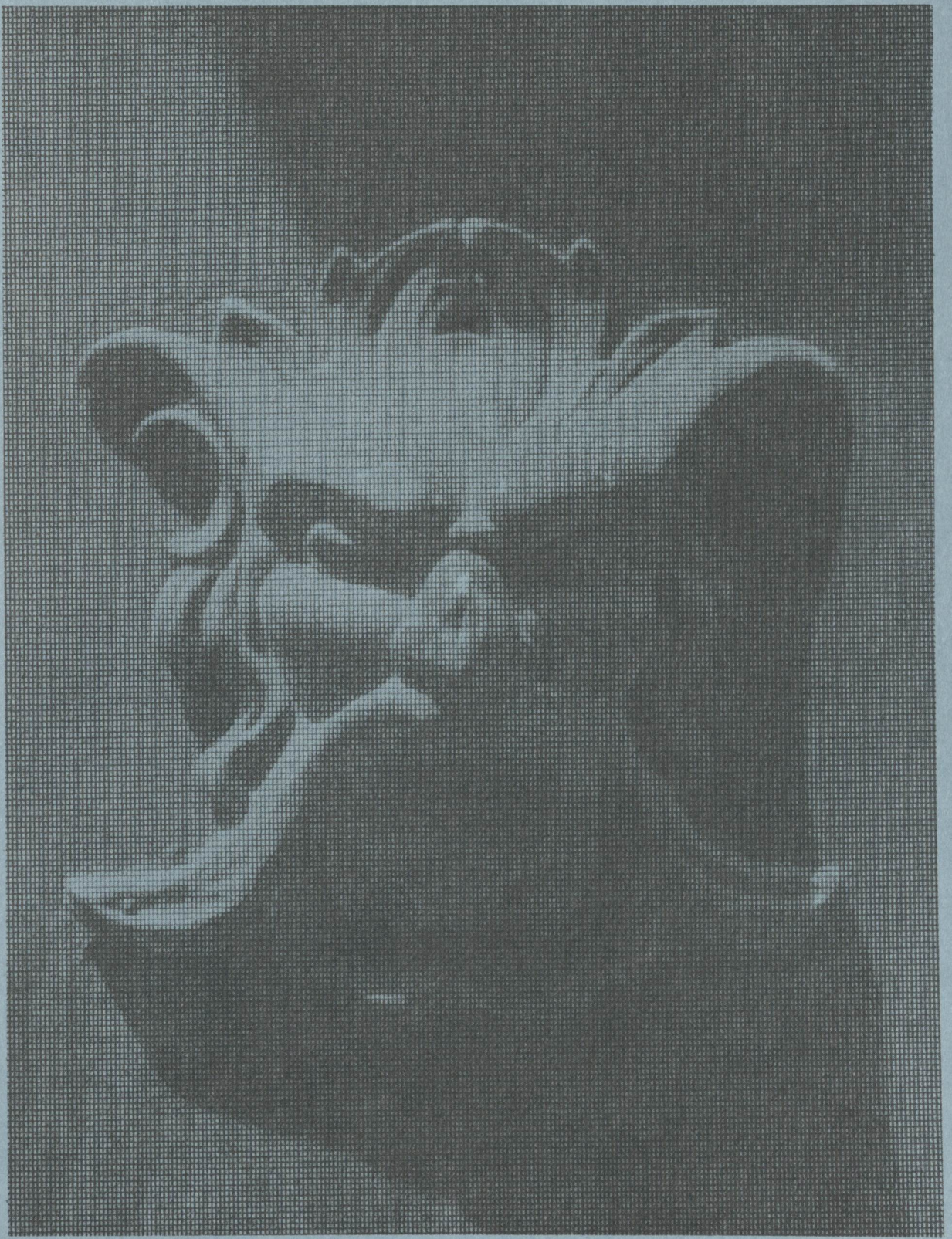


Chimères est une revue littéraire publiée par les étudiants gradués du Département de Français et d'Italien de $1^{\prime}$ Université du Kansas. Nous publions des articles scolaires, des poèmes, et des histoires qui sont en français ou en italien ou qui traitent de la littérature française ou italienne. Nous cherchons toujours des manuscrits de tous les étudiants de langue et de littérature.

Chimères paraît deux fois par an, en automne et au printemps. Le prix de 1 'abonnement pour 1 'année scolaire est de $\$ 2.00$ (ou $\$ 1.25$ par numéro). Adresser les chèques à Chimères.

Envoyez les manuscrits (en double), les abonnements, et toute correspondance à 1'Editeur, Chimères, P.0. Box 2093, Lawrence, Kansas 66044. 


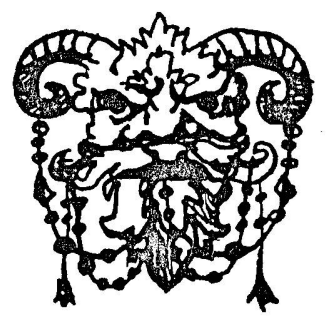

CHIMERES

Automne

Rédacteur:

Dana G. Clinton-Roper

Conseillers universitaires:

John T. Booker

C. de 1a Ménardière

Anne Lacombe

Joannès Pichon

Kenneth S. White

Collaborateurs:

Linda Davisson

Shirley Downer

Kathleen Gallagher

Lee Gerstenhaber

Laura Heller

Donna Chris Lorg

John E. Magerus

Jeffrey Osikowicz
Susan Ramsey

Jean Salien

Dorothy Jean Slentz

Carolyne Walters

Gene Ann Warneke

Elizabeth S. Witt

Geneviève M. Wolff

Micheline Woolard

Terrence Wright 


\section{TABLE DES ILLUSTRATIONS}

Couverture . . . . . . . . Norris Lacy Page 4 . . . . . . . . . . S. Sarsalin Page 11. . . . . . . . . Randy Breeden Page 17. . . . . . . . . . Mary Speagle Page 24. . . . . . . . Alfredo Sanchez Page 29. . . . . . . . Peter Dercher Page 38. . . . . . . . . Peter Dercher Page 48. . . . . . . . . Peter Dercher Page 53..... . . . . . . . Susan Parham Page 58. . . . . . . . . Peter Dercher Page 61............. . . . . . . Sandefur Page 62........... . . Susan Sifers Page 71. . . . . . . . . Joyce Hayashi Page 78. . . . . . . . . . Gary Samuelson Page 84.. . . . . . . . . . . . . . . . 0lson 


\section{TABLE DES MATIERES}

Karla Perrin: Réflexions . . . . . . . 5

EZizabeth Witt: L'Univers réduit des

Bâtisseurs d'empire. . . . . . . . 7

Kathleen Gallagher: Pastiches d'amour amoncelés. . . . . . . . . . 19

Terrence D. Wright: La Fonction du merveilleux dans trois pièces surréalistes . . . . . . . . . 21

Guy T. FiZosof: Connaissez-vous Sonkin?. . 30 Jan Pallister: Nostalgie . . . . . . 37

Laura HelZer: Le Style roman dans quelques pièces médiévales. . . . . . . . . 41

Jean-CZaude MuZZer: Ode aux parapluies . . 59

David Radd: Des Soies. . . . . . . . 60

Bob Brown: Le Malade se ranime . . . . 63

Jean M. Salien: Lettre à Dana Clinton-Roper

sur 1a littérature haïtienne . . . . 71

Jan Pallister: Un noiseau noir. . . . . 83 


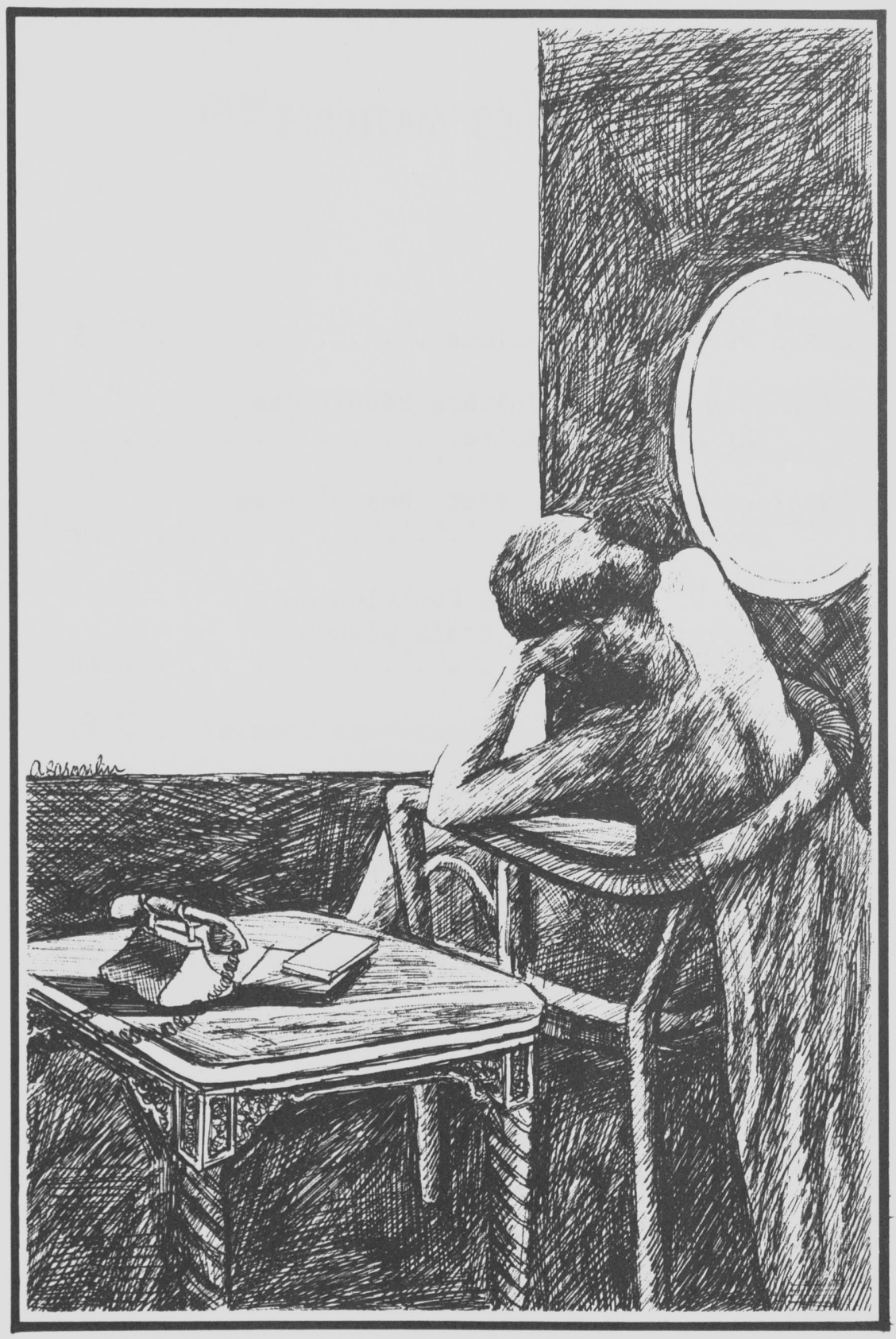

